\title{
Examining the moderating role of corporate social responsibility in the relationship between socially responsible consumption and quality of work life (QWL) of the staff in Social Security Organization
}

\author{
Mahdieh Rahmani $^{1^{*}}$, Akram Eghbali ${ }^{2}$ \\ ${ }^{1}$ Iranian Social Security Organization, Yazd, Iran \\ ${ }^{2}$ Department of Management, Yazd Branch, Islamic Azad University, Yazd, Iran
}

\begin{tabular}{|c|}
\hline $\begin{array}{l}\text { Keywords: } \\
\text { SRCO, CSR, QWL, } \\
\text { Organizational } \\
\text { commitment }\end{array}$ \\
\hline $\begin{array}{l}\text { Received } \\
27 \text { January } 2018\end{array}$ \\
\hline $\begin{array}{l}\text { Received in revised form } \\
\text { 08 June } 2018\end{array}$ \\
\hline $\begin{array}{l}\text { Accepted } \\
\text { 11 June } 2018\end{array}$ \\
\hline
\end{tabular}

Correspondence:

m.rahmani505@yahoo.com

\section{Abstract}

The main objective of this study was to examine the moderating role of corporate social responsibility in the relationship between socially responsible consumption and quality of work life (QWL) of the staff in Social Security Organization. The research model has been formed using variables such as socially responsible consumption, corporate social responsibility, QWL, and organizational commitment of the staff. Research methodology was a correlation type. The population of this research was the staff of Yazd Social Security Organization. Sampling method was stratified random, where the samples were selected from each class through simple random sampling. A questionnaire was used to collect data through which 290 valid samples were collected. In this study, data were analyzed using SPSS18 software. The relationships between variables and factors were examined by confirmatory factor analysis and structural equation modeling technique using PLS2 Smart software. Moreover, using Sobel test, we have examined the assumption of the mediator role of QWF. The results showed that corporate social responsibility and socially responsible consumption had an impact on the QWL. There was a significant relationship between corporate social responsibility (CSR) and QWL. The results also showed that CSR and socially responsible consumption (SRCO) affected organizational commitment through QWL. 


\section{Introduction}

When companies are getting bigger and bulkier and increasing in number, naturally, they have a major impact on the structure and social system. In other words, within a social structure and system, companies act as a social sub-system and are involved in a vast landscape and they exhibit a kind of mutual dependence. In recent years, given the growth of non-governmental organizations, protest movements against corporate power, increase in social awareness, development of capital markets and public companies, and financial and ethical scandals of large companies, the concept of CSR has become a dominant paradigm in the administrative space of the companies (Brown \& Dacin, 1997).

Organizational commitment is an important occupational and organizational attitude, which has been of interest to many researchers in the fields of organizational behavior and psychology, particularly social psychology over the past years. This attitude has undergone some changes during the past three decades and probably the most significant change in this regard is related to multidimensional approach to this concept rather than a one-dimensional one. One of the hidden but influential factors in job behavior of the employees is their commitment to the organization. Attention to the commitment of human resources, whether in public sector or private sector, is very important (Kthand \& Strasser, 2011).

Moreover, consumerism is one of the main obstacles to economic and social development rooted in cultural values of any society. Thus, high economic behavior is considered among the important cultural assets measured through indices such as responsible consumption and CSR (Bhattacharya \& Sen, 2004).

Today, QWL has been considered as a global concept in the field of human resource management and organizational development. The provision and upgrading of QWL are considered as the key to the success of management in any organization, and QWL is considered by senior managers as one of the techniques to organizational development (Pouravaz \& Sehat, 2010). Determining employees' QWL is important for employers who are interested in improving job satisfaction and employee commitment. The concept of employees' QWL, which is focused on since the time of neoclassical theorists, refers to components such as participation in work, supervision quality, job satisfaction, job security, reducing stress at work, the physical conditions of the workplace, reducing work accidents, paying sufficient and fair payment, and so forth (Sadr, 2011).

\section{Research Question}

This study aims to answer the following question:

How does CSR (organizational and personal beliefs) mediate the relationship between SRCO and QWL?

\section{Literature and Theoretical Foundations Organizational Commitment}

The term commitment in Merriam Webster dictionary means: 1) an act of depositing to an institution and 2) the agreement and commitment to do something in the future. Moreover, in behavioral science and organizational psychology, it means organizational commitment. Organizational commitment is an important occupational and organizational attitude, which 
has recently drawn much attention from many researchers in the fields of organizational behavior and psychology, particularly social psychology. However, this attitude has been subjected to some changes during the past three decades (Meyer \& Allen, 1991).

\section{Dimensions and Definitions of Organizational Commitment}

Some supporters of attitudinal approach refer to the organizational commitment as a multidimensional concept affected by different factors. Meyer and Allen (1991) are of the pioneers of multi-dimensional approach. Their three-dimensional model of organizational commitment includes affective, continuance, and normative dimensions. Organizational commitment is defined as loyalty to the organization. It is a concept achieved from recognition and the quality of the relationship of the individuals with their organizations (Kthand \& Strasser, 2011). Luthans (2002) argues that in recent research literature, the general attitude of organizational commitment is an important factor for understanding organizational behavior and a good predictor for tendency to stay in a job (Esmaili, 2001). Allen and Meyer (1990) believe that commitment is a mental state that is a tendency, need, and obligation to continue employment in an organization. As noted, these scientists have divided commitment to three dimensions of emotional commitment, continuance commitment, and normative commitment. Commitment have numerous positive consequences. Employees who have commitment have more discipline in their work, stay longer in the organizations, and work more. Managers should maintain employees' commitment and adherence to the organization, and for this, they should be able to use employees' participation in decision-making and provide an acceptable level of job security for them to increase commitment an adherence (Hosseini \& Mehdi Zadeh Ashrafi, 2010).

\section{Emotional commitment}

Meyer and Allen (1991) see emotional commitment as a person's emotional attachment to the organization and identification through it. The emotional commitment includes three aspects: A form of emotional attachment to the organization, willingness of the individual to be identified through the organization, desire to continue working in the organization.

Allen and Meyer (1990) argue that an individual will feel emotional attachment when he considers organizational goals as his own goals, and when he is convinced to help the organization in achieving its goals. They also explain that the person's identification through the organization happens when the individual values are consistent with organizational values and the individual is able to internalize organizational values. In this identification through the organization, there is a psychological relationship, and the person feels a kind of pride.

\section{Continuance Commitment}

The second organizational dimension from the viewpoint of Allen and Meyer (1990) is continuance commitment based on Baker's (1960) investment theory. According to this theory, the individual accumulates some capital in the organization over time and as the history of the individual in the organization becomes more, this capital becomes more accumulated, and losing it will be costlier for the individual. These investments include the acquisition of specific skills of the organization that are not transferable, working friendship, 
political factors, and other costs that discourage the individual from looking for alternative jobs. Allen and Meyer (1990) refer to continuance commitment as a form of psychological attachment of the individual to the organization that comes from employees' perceptions of things that he loses if he leaves the organization. In fact, it could be argued that continuance commitment includes one's awareness of the costs of leaving the organization. Therefore, in this form of commitment, the main reason for the individual's relationship with the organization and the decision to remain in it is an effort to maintain the benefits resulting from the relationship with the organization. Romzek (1990) considers this kind of dependence as a type of transaction. He believes that employees calculate their capital in the organization based on what they have given to the organization and what they will gain by staying in the organization. For example, a person may not prefer to change an organization for the sake of money and the time he has spent on a retirement.

\section{Normative Commitment}

The third dimension of organizational commitment, which is less common but can be discussed, is normative commitment. This type represents a sense of duty to continue cooperating with the organization. Those with a high level of normative commitment feel that they have to remain in the current organization (Allen \& Meyer, 1990). Fewer studies have been conducted in this dimensions of organizational commitment compared to other dimensions. For example, Randall \& Cote (1991), Allen and Meyer (1990), and O'Reilly, Chatman, and Caldwell (1991) have been among few researchers who have tried to distinguish this aspect of organizational commitment from the other dimensions. Randall and Kuti (1990) explore the normative commitment from the perspective of a moral duty that a person feels in him due to the investment the organization has done on him. They believe that this feeling arises in person when the organization has spent a lot of cost or time to prepare him for doing things better. Thus, a kind of feeling of duty to remain in the organization will be created. For example, an employee whose organization invests on his training may believe that he can return the favor by continuing to work in the organization. In general, normative commitment occurs more when the person feels that responding to the organization's investment is hard.

\section{Corporate Social Responsibility}

The formation of social responsibility goes back to the early decades of the twentieth century when the companies such as Ford and Karnych started to create non-profit institutions for the development of their communities. CSR received more attention in the 50s and 60s, when companies were faced with numerous questions about their role in society and several theories were offered in this area (Clark, 2000). In the 70s, CSR was considered in firms' real politics; for example, the role of stakeholders, including employees, suppliers, and local communities (Faryabi, Senobar, Ghodraty, \& Miandar, 2013). The 80s is important in terms of literature as new expressions and concepts such as Corporate Social Performance and Corporate Social Orientation have been proposed. In that decade, many researchers studied the impact of CSR on the profitability. The common point of all this is that social 
responsibility is seen as an opportunity for organizations. The idea that responsible and somite companies are profitable companies is the outcome of these studies (Carroll, 1999).

\section{Socially Responsible Consumption}

Social responsibility is viewed as the responsibility of the organization to influence its decisions and activities through transparent and ethical behavior on society and the environment.

Auger (2006) emphasized the role of responsible consumption in consumer behavior (staff) and considered it a deliberate choice for finalizing consumption choices based on personal and moral beliefs. As a suggestion, values used by a person that affect his work attitude can be pointed out. Employees with socially responsible consumption trends are worried about ethical and environmental consequences of buying and consumerism behavior (Antil, 1984). Consumerism is one of the main obstacles to economic and social development rooted in cultural values of any society. Thus, high economic behavior is considered among the important cultural assets measured through indices such as responsible consumption and CSR (Bhattacharya \& Sen, 2004). The results of the study by Brown and Dacin (1997) showed that the ability of the companies and CSR are as an important factors considered by consumers in the evaluation of companies (Iso 26000: 2010).

\section{Quality of Working Life}

The QWL is described as the ability of a product in meeting the target, which is produced with the least possible cost (Kamar, Alshawi, \& Hamid, 2009). The International Organization for Standardization for quality refers to all features of a product effective in its ability to satisfy stated or implied needs. From the above definitions, it can be concluded that what determines the quality of a product or a service is its compliance with the requirements, standards, and customer expectations. Improving employees' QWL is considered among the fundamental issues of management. Today, the particular attention paid to QWL is a reflection of the importance given to it by the public. To deliver their best efforts in realizing the goals of the organization, people are interested in knowing how their expectations, desires, needs, and dignity are dealt with. There are at least three common uses to this term. First, QWL refers to a set of results for employees such as job satisfaction, psychological growth opportunities, job security, good relations with the employer and employees, and fewer accidents. Perhaps this is the most common use for the term. Second, QWL also refers to a body of work or organizational functions such as participatory management, job enrichment, a payment system encouraging good performance, job security, and promising working conditions. Finally, QWL often refers to a type of organizational change program.

Considering the foregoing theoretical foundations, to achieve the research objective, the following hypotheses have been proposed and tested:

$\mathrm{H}^{1}$ : SRCO has a significant impact on QWL.

$\mathrm{H}^{2}$ : CSR has a significant impact on QWL.

$\mathrm{H}^{3}$ : QWL has a significant impact on organizational commitment.

$\mathrm{H}^{4}$ : SRCO has a significant impact on organizational commitment.

$\mathrm{H}^{5}$ : CSR has a significant effect on organizational commitment. 
$\mathrm{H}^{6}$ : CSR adjusts the effect of CSR on QWL.

According to the theoretical framework and hypotheses, the model is as follows:

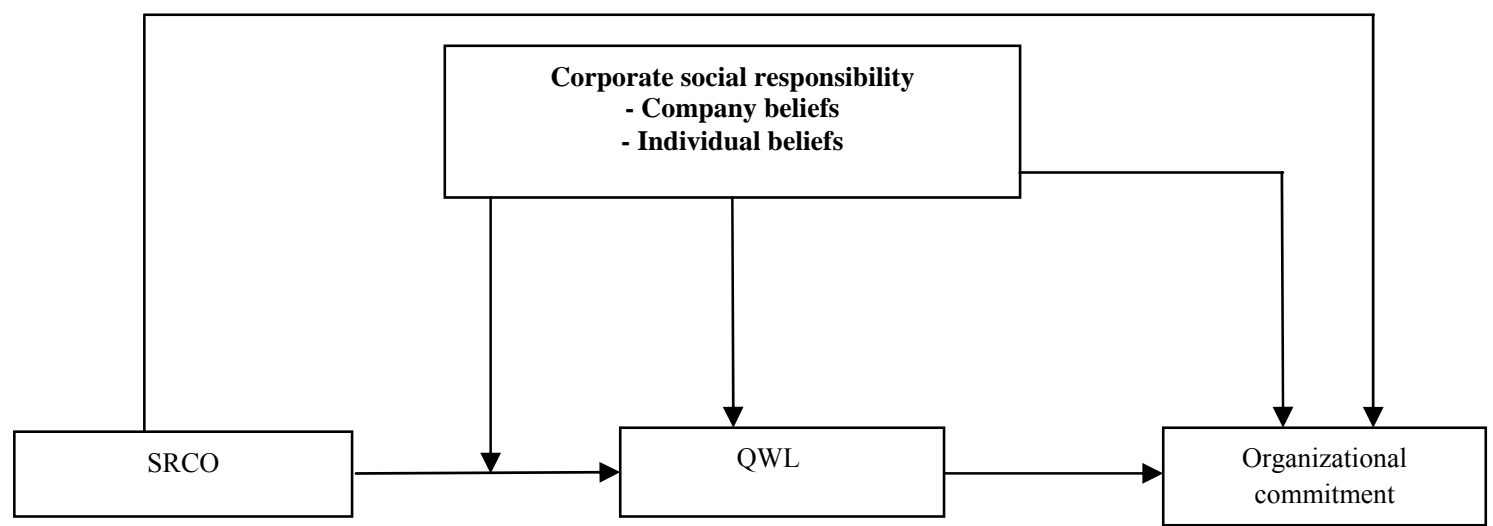

Figure 1. The proposed conceptual model (Arndt, Singhapakdi, \& Tam, 2015; Singhapakdi, Lee, Sirgy, \& Senasu, 2015)

\section{Method}

The research method is survey. Survey studies seek to investigate the distribution of the characteristics of a society and society parameters. This is conducted as cross-sectional. Therefore, according to the argument provided, this research is non-experimental and correlational.

\section{Population and Sample}

The population is all employees Social Security Organization (SSO) in Yazd, including 1157 personnel of different parts of SSO. According to Table 1, considering the population size of each department in the organization, with the help of stratified sampling in specified classes, the following sample was selected:

Table 1

Sample Size in each Sector according to the Number of Personnel

\begin{tabular}{lcc}
\hline Classes & Population & Sample \\
\hline Expert hand & 397 & 99 \\
Technician & 92 & 23 \\
Expert & 558 & 139 \\
Responsible & 81 & 20 \\
Manager & 29 & 7 \\
Total & 1157 & 290 \\
\hline
\end{tabular}

\section{Instruments}

In the present study, survey method and a questionnaire were used to collect the data. The questionnaire is in a 5-point Likert scale (from 1 strongly disagree to 5 strongly agree). It consists of 33 questions. The following number of items are used to measure the variables: SRCO, three items (Arndt et al., 2015); organizational commitment, 3 items (Arndt et al., 2015); CSR (including 7 items for corporate beliefs and 4 items for personal beliefs (Singhapakdi et al., 2014)); QWL, 16 items (Singhapakdi et al., 2015). 
Table 2 shows the Cronbach's alpha and the number of questions in the questionnaire and the questionnaire variables. Since Cronbach's alpha of the questionnaire is greater than.7, the test has acceptable reliability.

Table 2

Reliability of the Questions Related to the Questionnaire

\begin{tabular}{cccc}
\hline Cronbach's alpha & Number of the questions & Questions of the questionnaire & Variable \\
\hline .72 & 3 & 1 to 3 & Organizational commitment (OC) \\
.77 & 3 & 4 to 6 & SRCO \\
.80 & 11 & 7 to 17 & CSR \\
.88 & 16 & 18 to 33 & QWL \\
.85 & 33 & - & Whole questionnaire \\
\hline
\end{tabular}

\section{Data Analysis}

In this study, one sample t-test was run on the data using SPSS18 software. The relationships between variables and factors was examined through confirmatory factor analysis and PLS modeling technique using PLS2 Smart software, which is a variance-oriented path modeling allows to study the assumptions and indices simultaneously, and the moderator variable. This method is used in cases where the model is complex, sample size is small, or variable distribution is not normal. Moreover, we ran Sobel test to examine the assumption of the mediator role of QWL.

\section{Findings}

\section{Comparison of the Study Variables with Mediocrity Measure}

One sample t-test for comparing the observed means of variables with theoretical means of the measurement scale indicated that despite the significance level smaller than .05 , the mean of all variables is significantly different from the theoretical mean. According to the estimated means for variables, it can be concluded that the means for OC, SRCO, CSR, and QWL are greater than 3, significantly higher than average.

Table 3

One Sample T-Test for Variables Comparing the Observed Mean with a Constant Value of 3

\begin{tabular}{lccccc}
\hline Variable & The estimated mean & $t$ & $d f$ & $p$ & $M$ \\
\hline OC & 3.29 & 6.12 & 288 & .001 & .29 \\
SRCO & 3.56 & 12.56 & 288 & .001 & .56 \\
CSR & 3.48 & 15.76 & 289 & .001 & .48 \\
QWL & 3.22 & 6.14 & 289 & .001 & .22 \\
\hline
\end{tabular}

\section{The Main Model}

In this study, structural equation modeling with the help of partial least squares method and PLS Smart software were used to test the hypotheses and the integrity of the main model. This method is used in cases where the sample size is small or the distribution of the variable is not normal. In PLS models, two models are tested. The external model is equivalent to measurement model and the internal model is similar to structural model in structural equation models. The external model shows factor loadings of the observed variables. 


\section{The External Model (Measurement Model)}

In structural equation modeling methodology, it is initially necessary to examine if the items selected to measure variables have the desired accuracy. For this purpose, confirmatory factor analysis (CFA) is used. The factor loading should have a value higher than 1.96. In this study, the items have the necessary accuracy to measure that structure or latent variable. In Table 4, the values of factor loading for the items in each latent variable are given.

Table 4

Confirmatory Factor Analysis (Factor Loading Values and T Value) for Variables

\begin{tabular}{|c|c|c|c|c|}
\hline Variable & Item & Factor loading & Standard error & $t$ \\
\hline \multirow{3}{*}{$\mathrm{OC}$} & Q1 & .71 & .06 & 10.75 \\
\hline & Q2 & .81 & .04 & 18.16 \\
\hline & Q3 & .74 & .05 & 13.26 \\
\hline \multirow{4}{*}{ SRCO } & Q4 & .72 & .07 & 9.04 \\
\hline & Q5 & .69 & .07 & 9.91 \\
\hline & Q6 & .78 & .05 & 14.21 \\
\hline & Q7 & .70 & .04 & 17.18 \\
\hline \multirow{9}{*}{ CSR } & Q8 & .67 & .05 & 12.94 \\
\hline & Q9 & .67 & .05 & 13.31 \\
\hline & Q10 & .45 & .06 & 7.48 \\
\hline & Q11 & .68 & .05 & 12.31 \\
\hline & Q12 & .74 & .04 & 16.15 \\
\hline & Q13 & .57 & .07 & 7.44 \\
\hline & Q14 & .32 & .09 & 3.62 \\
\hline & Q15 & .36 & .09 & 3.81 \\
\hline & Q16 & .62 & .07 & 8.66 \\
\hline \multirow{17}{*}{ QWL } & Q17 & .51 & .08 & 6.05 \\
\hline & Q18 & .53 & .06 & 8.02 \\
\hline & Q19 & .61 & .05 & 10.24 \\
\hline & Q20 & .40 & .08 & 4.74 \\
\hline & Q21 & .58 & .06 & 9.72 \\
\hline & Q22 & .62 & .06 & 9.60 \\
\hline & Q23 & .64 & .05 & 11.41 \\
\hline & Q24 & .35 & .08 & 4.32 \\
\hline & Q25 & .60 & .05 & 10.27 \\
\hline & Q26 & .75 & .03 & 22.23 \\
\hline & Q27 & .53 & .06 & 7.88 \\
\hline & Q28 & .71 & .03 & 18.21 \\
\hline & Q29 & .63 & .05 & 11.16 \\
\hline & Q30 & .68 & .04 & 14.60 \\
\hline & Q31 & .72 & .04 & 16.51 \\
\hline & Q32 & .60 & .06 & 9.99 \\
\hline & Q33 & .67 & .05 & 12.13 \\
\hline
\end{tabular}

All of the items had t statistic greater than 1.96; thus, none of the items is removed from the model, and the model is evaluated with all the items (questions) included. On the other hand, according to factor loading, the index that has the highest factor loading has a higher share in measuring the related variable, and the index with smaller coefficients has less contribution to the measurement. 
Using the internal model, one can examine the hypothesis. By comparing the $t$ value calculated of the coefficient for each path, one can confirm or reject the hypotheses of the study, i.e., if the absolute value of the t-statistic is greater than 1.96 , at confidence level $95 \%$, and if the value of t-statistic is more than 2.58 , the path coefficient is significant at $99 \%$ confidence level. The results of testing the conceptual model are shown in figure 2 .

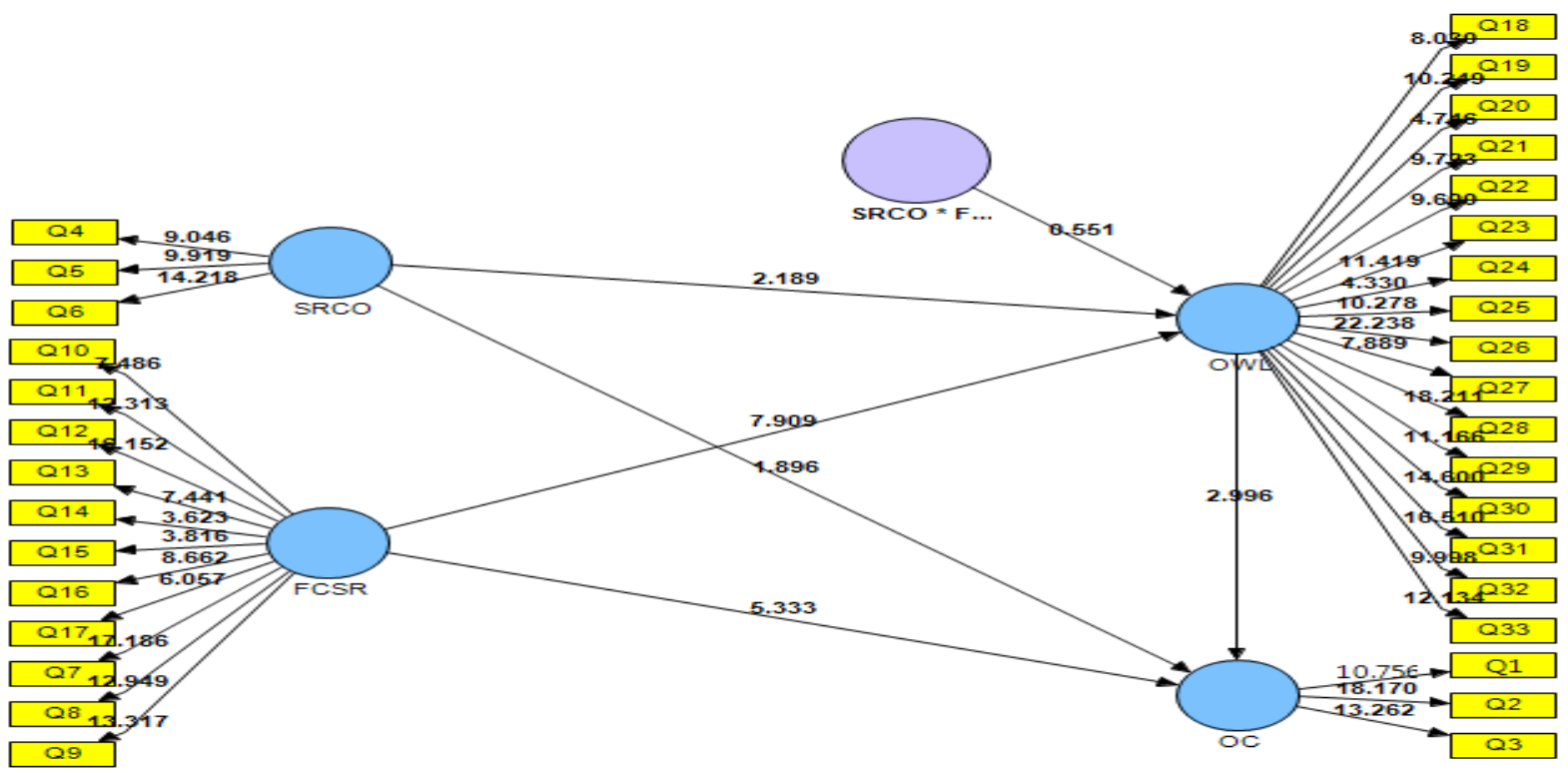

Figure 2. The main model in significant numbers case (t-value)

The numbers on the paths show t-value for each path. To determine the significance of the path coefficients, it is necessary for the $t$ statistic value to be higher than 1.96. In this analysis, the t-statistic value for all paths, except SRCO to OC and the mutual path for SRCO and CSR, is higher than 1.96 and significant at $95 \%$ confidence level.

Numbers written on the lines are the beta coefficients of the regression equation between variables in the same path. The numbers in each circle represent the value of R2 of the model whose predictive variables enter the circle via the arrow. Coefficient of determination for QWL is estimated as .33 and shows that SRCO and CSR altogether could explain 33\% of variation of QWL. According to standard coefficient and $\mathrm{t}$ statistics, it can be argued that CSR (.44) and SRCO (.17) had the highest impact on QWL (the highest path coefficient). Moreover, QWL, SRCO, and CSR explain $42 \%$ of the changes of organizational commitment. The CSR compared to QWL had a greater impact on organizational commitment, and SRCO has no significant effect. 


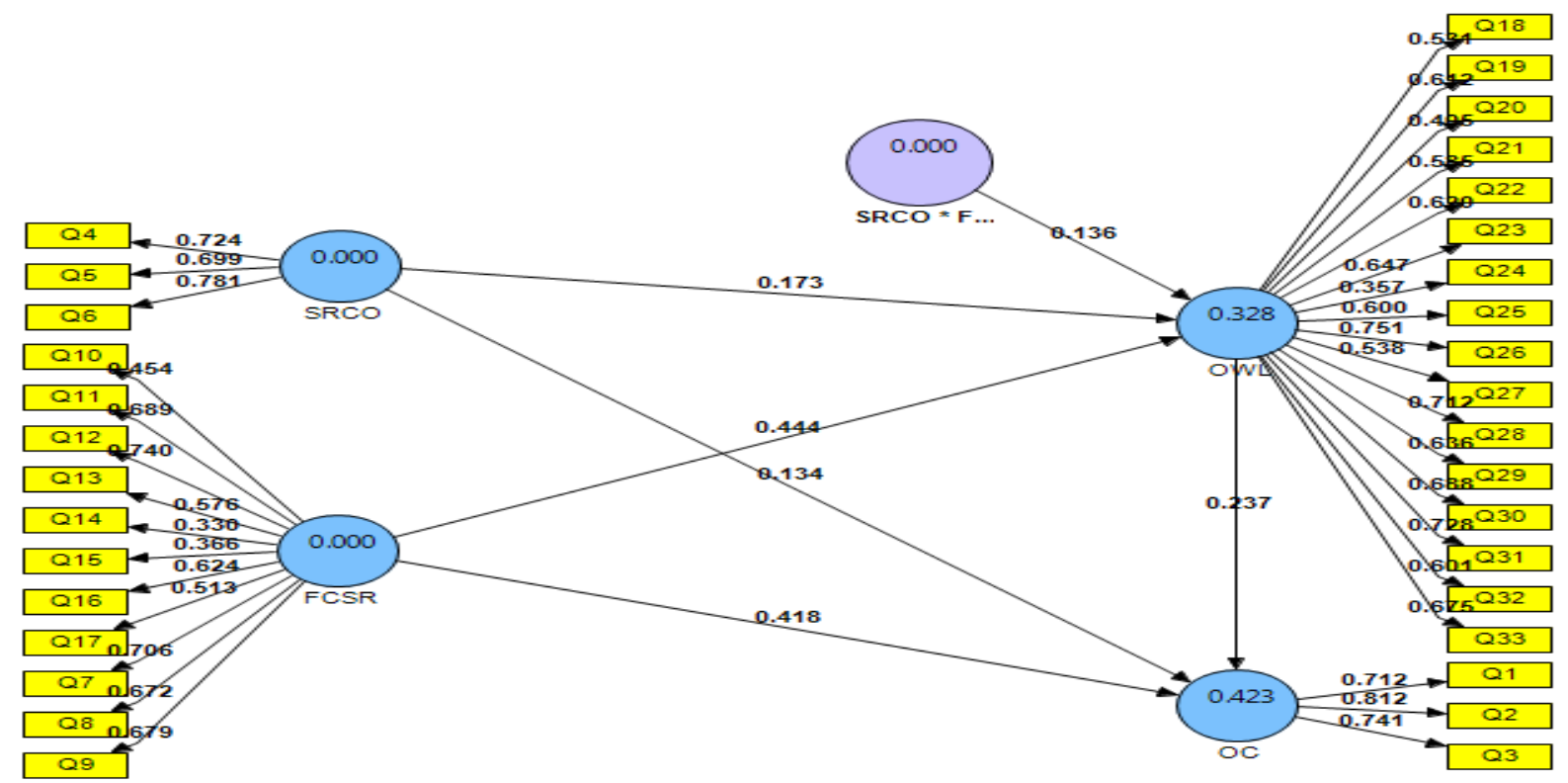

Figure 3. The main model in path coefficient case

\section{Internal Model (Structural Model)}

In the form of an internal model, the hypotheses were examined and the structural model path was evaluated. Each path corresponds to one of the hypotheses of the model. Testing each hypothesis was done by examining the sign, value, and the significance of path coefficients statistic (beta) between each latent variable and the dependent variable. As the value of this path coefficient was higher, the predictive impact of the latent variable compared to the dependent variable was higher.

To evaluate the significance of path coefficient or beta, the significance of $t$-value for each path coefficient must be taken into account. Thus, Bootstrapping method was used. For this purpose, resampling was simulated in 500 and 800 samples. The results showed that the significance or insignificance of the parameter change and the results were not reliable in none of the cases.

Table 5

Direct Linear Effect of the Variables in the Main Model

\begin{tabular}{|c|c|c|c|c|c|c|}
\hline \multirow{2}{*}{ Path } & \multirow{2}{*}{$\beta$} & \multirow{2}{*}{$M$} & \multirow{2}{*}{ Standard error } & \multicolumn{3}{|c|}{ Resampling t statistic value } \\
\hline & & & & 200 & 500 & 800 \\
\hline $\mathrm{SRCO} \leftarrow \mathrm{OWL}$ & .17 & .15 & .06 & 2.18 & 2.38 & 2.26 \\
\hline FCSR $\leftarrow \mathrm{OWL}$ & .44 & .43 & .05 & 7.90 & 7.60 & 7.02 \\
\hline SRCO $*$ FCSR $\leftarrow O W L$ & .13 & . 10 & .24 & .55 & .58 & .58 \\
\hline $\mathrm{OWL} \leftarrow \mathrm{OC}$ & .23 & .22 & .07 & 2.99 & 2.81 & 2.86 \\
\hline $\mathrm{SRCO} \leftarrow \mathrm{OC}$ & .13 & .14 & .07 & 1.89 & 1.88 & 1.89 \\
\hline $\mathrm{FCSR} \leftarrow \mathrm{OC}$ & .41 & .43 & .07 & 5.33 & 5.23 & 5.80 \\
\hline
\end{tabular}

As presented in Table 5, T-statistic for all paths, except SRCO to OC and the mutual path for SRCO and CSR, was higher than 1.96 showing 95\% confidence level. Thus, it had a significant effect except for SRCO to OC and the mutual path for SRCO and CSR. 
Table 6

Summary of Path Coefficients of Determination, T Statistic and the Result of the Main Model

\begin{tabular}{lcccc}
\hline The hypotheses of the main model & Path coefficients & $t$ & Coefficients of determination & Result \\
\hline SRCO $\rightarrow$ QWL & .17 & 2.19 & .33 & Confirmed \\
CSR $\rightarrow$ QWL & .44 & 7.91 & & Confirmed \\
QWL $\rightarrow$ OC & .24 & 2.99 & .42 & Confirmed \\
SRCO $\rightarrow$ OC & .13 & 1.90 & Rejected \\
CSR $\rightarrow$ OC & .41 & 5.33 & Confirmed \\
\hline
\end{tabular}

$\mathbf{H}_{6}$ : CSR adjusts the effect of CSR on QWL.

To investigate the moderator role of CSR in the main model, we insert the product of SRCO and CSR into the model. If the relationship between these two variables is significant, the moderator role of CSR is confirmed.

Table 7

For The Sixth Hypothesis

\begin{tabular}{lccc}
\hline Path & Coefficient & Standard error & $t$ \\
\hline SRCO $\leftarrow$ OWL & .17 & .07 & 2.18 \\
FCSR $\leftarrow$ OWL & .44 & .05 & 7.90 \\
SRCO*FCSR $\leftarrow$ OWL & .13 & .24 & .55 \\
\hline
\end{tabular}

The $t$ statistic value for the interaction between CSR and SRCO was .55. As the absolute value of the t-statistic was smaller than 1.96, thus the null hypothesis was not rejected, which means CSR did not moderate the effect of SRCO on QWL.

\section{Discussion and Conclusion}

$\mathbf{H}_{\mathbf{1}}$ : SRCO has a significant impact on QWL.

According to the result of testing the hypotheses at 95\% confidence level, SRCO had a significant impact on QWL and the value of the effect was .17 and positive (direct). This means that with increase in SRCO, the QWL also increases. The result of this hypothesis is consistent with Arndt et al.'s (2015) study.

$\mathbf{H}_{2}$ : CSR has a significant impact on QWL.

Given the result of the second hypothesis and data analysis, at 95\% confidence level, CSR had a significant impact on QWL and the value of the effect was .44 and positive (direct). This means that with increase in CSR, the QWL also increases. The result of this hypothesis is consistent with the study conducted by Arendt et al. (2015).

$\mathbf{H}_{3}$ : QWL has a significant impact on organizational commitment.

According to the result of testing the third hypotheses at 95\% confidence level, QWL had a significant impact on $\mathrm{OC}$ and the value of the effect was .24 and positive (direct). This means that with increase in QWL, OC also increases. The result of this hypothesis is consistent with research conducted by Arendt et al. (2015), Nabati (2012), and Sadr and Ghamari (2011).

$\mathbf{H}_{4}$ : SRCO has a significant impact on organizational commitment.

The result of the fourth hypothesis has shown that at 95\% level of confidence, SRCO had no significant effect on OC. In other words, in the treatment department of Yazd Social Security 
Organization and the studied sample, SRCO had no effect on employee commitment to the organization.

$\mathbf{H}_{5}$ : CSR has a significant effect on organizational commitment.

Given the result of testing the fifth hypotheses at $95 \%$ confidence level, CSR had a significant impact on OC and the value of the effect was .41 and positive (direct). This means that with increase in CSR, OC also increases.

In fact, in treatment department of Social Security Organization of Yazd Corporate Social Responsibility had an impact on employee commitment to the organization. In research by Mortazavi et al. (2010), Arndt et al. (2015), Anthony and Hong (2014), Peterson (2004), Lee, Seo, and Sharma (2013), this hypothesis has been approved.

$\mathbf{H}_{6}$ : CSR adjusts the effect of CSR on QWL.

The results of testing the hypotheses show that CSR did not adjust the effect of SRCO on QWL.

\section{Practical Suggestions}

This study examined the effect of SRCO, CSR, and QWL on organizational commitment of the employees in Yazd Social Security Organization. The results revealed the existence of a relationship between SRCO and QWL. Thus, it can be argued that with increase in SRCO, the quality of work life significantly increases as well. Therefore, it is suggested that the directors of SSO pay attention to the employees' health in the workplace. Moreover, it is suggested that the necessary training of SRCO to the staff should be given. Sufficient bonuses and salaries must be given to the staff in return for their efforts. It should be noted that the employees' responsibilities should be in the field of their expertise and capabilities, so that they feel that their job provides the opportunity for them to use all their abilities. Moreover, more investment is suggested on the environmental activities.

The results of the second hypothesis indicated that the level of CSR had a significant effect on QWL of the staff. Thus, senior management should see the organization as improving the quality of life and general welfare of the society and staff, and he should consider measures in this regard. In that case, the employees of SSO will always think that they are work for an organization with social responsibility that offers significant services to the society. It is recommended that the organizations develop its activities in the field of social responsibility and allocate adequate resources and funding. The organization should consider reward for the activities that employees perform in the field of social responsibility.

The results of the third and fourth hypotheses revealed that QWL had a significant effect on OC, and SRCO had no significant effect on OC. The following measures should be taken to improve QWL: Special attention should be paid to the balanced role of work and providing the means to meet the basic needs of employees' families; efforts should be made to reform the stress factors in the workplace and improve the physical conditions of the workplace; paying and salaries should be adequate and fair; employees' job should be designed in such a way that does not prevent his carrying out duties and family responsibilities and social roles; the organization should provide the possibility of the growth of potentials and abilities and realize it by providing the opportunity to show the skills learned and guarantee a sustainable job security and assurance of income; work environment should be designed in way that 
people have freedom of expressing ideas and feelings and the context should be provided for intellectual and practical participation, job design in the organization should be in a way that fits everyone's conditions, and healthy and safe environmental conditions should be provided for employees; the recreational camps and happy and fun programs for employees and their families should be held; a part of the health care costs, including dental costs as well as contracts with supplementary insurance should be paid.

The results of the fifth hypothesis indicated that at 95\% level of confidence, CSR had a significant impact on organizational commitment. The organization should consider the concept of social responsibility as an opportunity which offers an option for sustainable and more growth. Continuous learning programs should be considered for this concept. It is also suggested that the measures of CSR should be in line with the organization's goals and core competencies. It is recommended that organization managers institutionalize the concept of social responsibility in the corporate culture.

\section{References}

Allen, N. J., \& Meyer, J. P. (1990). The measurement and antecedents of affective, continuance and normative commitment to the organization. Journal of occupational and organizational psychology, 63(1), 1-18.

Anthony, W. I., \& Hong, G. J. (2014). Exploring the direct and indirect effects of CSR on organizational commitment. International Journal of Contemporary Hospitality Management, 26(4), 525-550.

Antil, J. H. (1984). Socially responsible consumers: Profile and implications for public.

Armstrong, S. J. (2013). Human plasma-derived BuChE as a stoichiometric bio scavenger for treatment of nerve agent poisoning, Chemico-Biological Interactions, 203(1), 160-166.

Arndt, A. D., Singhapakdi, A., \& Tam, V. (2015). Consumers as employees: The impact of social responsibility on quality of work life among Australian engineers. Social Responsibility Journal, 11(1), 98-108

Azour, H., \& Kazemi, M. (2014). Identifying the impact of corporate social responsibility on quality of employees' relationships and its consequences. Journal of Commercial Management, 6(4), 685-665.

Bhattacharya, C., \& Sen, S. (2004). Doing better at doing good: When, why and how consumers respond to corporate social initiatives. California Management Review, 47(1), 9-24.

Biker, T. S., \& Organ, D. W. (1996). Job satisfaction and the professional commitment: The relationship between affect and employee "citizenship." Academy of Management Journal, 26, 587-595

Brown T., \& Dacin, P. (1997). The company and the product: Corporate associations and consumer product responses. Journal of Marketing, 61(1), 68-84.

Carrol, A. B. (1979). A three-dimensional conceptual model of corporate social performance". Academy of management review, 4, 496-505

Carroll, A. B. (1999). Corporate social responsibility: Evolution of a definitional construct. Business and Society, 38, 268295.

Clark, C.E. (2000). Differences between public relations and corporate social responsibility: An analysis". Public Relations Review, 26(13), 363-381.

Esmaeili, K. (2001). Organizational commitment, Tadbir Magazine, No. 112.

Faryabi, M., Senobar, N., Ghodraty, A., \& Miandar, F. (2013). A study on the impact of corporate responsibility on responsible consumption, Two Issues of Sociology of Economics and Development, 3(2), 97-119.

Friedman, M. (1970). The social responsibility of business is to increase its profits. New York Times Magazine, September, 13(32-33), 122-124

Heald, M. (1991). The Social Responsibilities of Business: Company and Community, 1900-1960, Journal of Business Ethics, 10(1), 71-75.

Hoobler, J. M., Wayne, S. J., \& Lemmom, G. (2009). Bosses perception of family -work conflict and women s promotability class ceiling effects. Academy of Management Journal, 52, 939-945 
Hosseini, S. M., and Mehdi Zadeh Ashrafi, A. (2010). identification of factors affecting organizational commitment. Management Quarterly (Researcher), 7(18), 9-16.

Kamar, K.A. M., \& Alshawi, M, \& Hamid, Z. (2009). Industrialised building system (IBS): The critical success factors and way forward. Paper presented at the 2nd CIDB.CREAM IBS Roundtable Workshop. Kuala Lumpur: CIDB

Kthand, G. Strasser. I. K. (2011). Factors related to the organizational and professional commitment of internal auditors. Management Auditing Journal, 19(5), 606-622

Ladson-Billings, G. J. (1996). Silences as weapons: Challenges of a Black professor teaching white students. Theory into Practice, 35(2), 79-85

Lai C. S., Chiu C. J., Yang, C. F., \& Pai, D. C. (2010). The effects of corporate social responsibility on brand performance: the mediating effect of industrial brand equity and corporate reputation. Journal of Business Ethics, 95, 457-469.

Lee, S., Seo, K., \& Sharma, A. (2013). Corporate social responsibility and firm performance in the airline industry: The moderating role of oil prices. Tourism Management, 38, 20-30.

Luthans, F. (2002). The need for and meaning of positive organizational behavior. Journal of organizational behavior, 695706.

Meyer, J. P., \& Allen, N. J. (1991). A three-component conceptualization of organizational commitment. Human resource management review, 1(1), 61-89.

Moorhead, G. (2003). Organizational behavior, translated by Seyed Mahdi Alwani and Gholam Reza Memarzadeh. Tehran, Morvarid Publications.

Nabati, M. (2012). Exploring the relationship between QWL and its dimensions with organizational commitment and quality of life and its dimensions in veteran and new physical education teachers (Unpublished Master's thesis). Islamic Azad University, Tehran.

O’Reilly, C. A., Chatman, J., \& Caldwell, D. F. (1991). People and organizational culture: A profile comparison approach to assessing person-organization fit. Academy of Management Journal, 34, 487-516.

Peterson, D. K. (2004). The relationship between perceptions of corporate citizenship and organizational commitment. Journal of Business and Society, 43(3), 296-319.

Pouravaz, H., \& Sehat, M. (2010). Reviewing the effectiveness of management accounting information on improving the quality of strategic decision-making process of managers, case study Momtaz and Meshkin Groups of matches factories. Paper presented at the International Conference on New Directions in Management, Economics and Accounting, Iran.

Randall, D. M., \& Cote, J. A. (1991). Interrelationships of work commitment construct. Work and Occupations, 18, 194211.

Romzek, B. S. (1990). Employee investment and commitment: The ties that bind. Public Administration Review, 50, 374382.

Sadr, M., \& Ghamari, S. (2011). Investigating the relationship between quality of work life and organizational commitment Sopko engineering design company (Unpublished Master's thesis). PNU: Tehran.

Singhapakdi, A. Lee, D-J., Sirgy, M. J., \& Senasu, K. (2015). The impact of incongruity between an organization's CSR orientation and its employees' CSR orientation on employees' quality of work life. Journal of Business Research, 68(1), $60-66$. 